\title{
Design urbano e as rupturas da arte contemporânea na anarcoarquitetura de Gordon Matta-Clark
}

\author{
Mayra Ferreira Mártyres Alexander \\ Mirtes Marins de Oliveira \\ Universidade Anhembi Morumbi
}

\begin{abstract}
Resumo
O presente artigo busca elaborar um paralelismo, e possíveis conexões e antagonismos, entre uma perspectiva modernista que enfatiza as cidades projetadas e a produção artística de Gordon Matta-Clark (1943-1978), que durante a década de 1970 questionou a utilização do espaço urbano por oposição ao modelo de urbanização modernista e em contexto do capitalismo daquela década. A descaracterização das cidades, reestruturadas com finalidades de fluxo das mercadorias, seu consumo e privilégio de classes sociais ligadas à tais interesses, também apontou para o debate acerca do patrimônio cultural. Este cenário levou a uma pesquisa em duas áreas, uma focada na captação de eventuais rupturas ocorridas na arte contemporânea relacionadas à urbanização, e a segunda, questionando os conceitos tradicionais de museus sobre a apropriação do espaço público, possibilitando assim, uma reflexão sobre novas funções dos museus neste contexto.
\end{abstract}

Palavras-chave: Design Urbano. Arte. Gordon Matta-Clark. Museu.

\section{Introdução}

A categoria explicativa denominada design urbano tem referência na transformação do "caos natural em um cosmo humano desenvolvendo estratégias de organização e domínio do espaço" (SCHULZ, 2008) e se inicia com a ampliação das cidades, da economia, da composição das concepções filosóficas e das características científicas encontradas na sociedade no XVII e XVIII (SCHULZ, 2008, p. 10)

Em contexto da presente pesquisa, a partir do debate sobre a materialidade da cidade e sua apropriação pelos diferentes públicos, buscou-se uma aproximação ao design das cidades assim como aos processos de estudos sobre a "cidade ideal" se desenvolveram ao longo da história ocidental, documentando mudanças sociais e econômicas que são também amparadas por mudanças de pensamento sobre projetos da urbe. É possível considerar, e essa é uma premissa da pesquisa, que a discussão sobre esses projetos, aliados aos processos de descaracterização das cidades, também estimulou reflexões acerca da importância histórica das cidades e sua manutenção que, especificamente nos anos 1970 
(Conselho da Europa, na Carta Europeia do Patrimônio Arquitetônico no 1), ampliou o conceito de patrimônio para ambientes humanizados e edificados.

Do ponto de vista histórico, o design urbano, influenciado por reformas políticas, religiosas e imposições comportamentais, pode ser apontado na criação dos espaços públicos e privados, que têm origem na centralização das cidades em praças públicas na Europa nos sécs. VII e VIII, consequência da reorganização política e espacial, como descreve Schulz (2008, p. 24-25):
A centralidade da cidade deslocou-se para a ágora, a praça pública, um espaço igualitário e comum, destinado à confrontação e argumentação, para onde migraram os poderes do soberano. [...] A polis, a cidade-estado grega, trouxe a público eventos de enorme relevância para a vida social, instalando um domínio público como lugar de interesse comum, em oposição a assuntos privados, e também como lugar de práticas abertas, em oposição a processos secretos.

Com referências na Grécia e Roma da Antiguidade, o design urbano se aprimorou e adaptou às características culturais de cada região, tratando-se, portanto, de processo dinâmico. Mas, com os estudos dos traçados urbanos, que questões da cidade como espaço idealizado, se iniciaram, articulando a vida dos indivíduos e da comunidade, como descreve Roseau (1988, p. 19):

O plano ideal refere-se ao sítio como uma unidade e exprime as aspirações, mais que as realizações, de uma civilização em particular; destina-se a circunstâncias variadas, e é-lhes aplicável. A sua alternativa é o desenho funcional destinado a um lugar e objetivo particulares. Assim, a imagem da cidade ideal procura a resposta universal para problemas temporários e, ao fazê-lo, reflete o seu pano de fundo social assim como o desafia.

Da perspectiva de uma cidade ideal como um projeto de controle social, encontrar-se-á uma cidade ideal com mecanismos urbanos de controle, e que, ao serem implantados nas cidades reais, geraram resistência e consequentemente o fracasso desses projetos, como descreve Schulz (2008, p. 58), "as cidades reais fazem emergir infinitas potências, diferenças que expandem incessantemente os limites existentes", ou seja, as cidades ideais não poderiam ser vistas como um campo imutável, e sim um campo expandido, além dos traçados dos arquitetos. Nesse período, os planejadores não compreendiam a cidade como um projeto multidisciplinar, no qual a própria população com seus grupos e funções faziam distintos usos da cidade projetada, mas como um aprimoramento espacial no sentido do interesse de governantes e poderosos.

A discussão sobre o traçado urbano das cidades gerou propostas de cidades ideais baseadas em experiências urbanísticas. As narrativas históricas sobre a produção artística dos sécs. XVII e XVIII, como descreve Schulz (2008), em decorrência da expansão científica, da crise política e econômica, reconhece que a atuação dos arquitetos foi duplamente 
importante quanto ao valor estético, já que se expressavam na arquitetura de forma sensual e fluida e nos traçados geométricos dos planos urbanos, com a rigidez e a ciência matemática.

As questões urbanas ainda estavam comprometidas devido ao crescimento demográfico e à capacidade dos países em solucionar os problemas de moradia, tanto ao que diz respeito ao saneamento, quanto à habitação, além dos iniciais processos de industrialização europeia. Assim, a expansão das cidades rapidamente alcançava limites além do planejado pelos governantes e um novo problema se instaurou nas cidades industriais em proporções ainda maiores, devido ao crescimento desordenado e à falta de planejamento para áreas em expansão em contexto de espaços que construídos em modelo medieval.

É nesse momento, a partir do século XVIII e principalmente XIX, que se tem conhecimento dos primeiros relatos do urbanismo sanitarista, cujo objetivo seria o de melhorar as condições das cidades quanto a sua salubridade para conter o avanço de graves problemas de saúde pública, causados pela falta de esgoto e poluição de rios. Assim, em 1848 foi criada a primeira lei sanitária na Inglaterra, a Public Health Act., que tinha como base a atuação pública no espaço urbano através do abastecimento de água, canalização de esgotos, abertura de vias sanitárias e outros detalhes para o bem-estar dos cidadãos e das cidades, considerando como premissa a otimização da produção industrial.

A implantação e o aperfeiçoamento das leis sanitárias, desencadearam o desenvolvimento de políticas e legislações especificas de caráter urbanístico, nas quais iriam ser descritos os critérios de loteamentos, distância entre as edificações, sua altura, espaços e aberturas, dentre outros, com o intuito de criar um ambiente salubre e adequado para se viver segundo essa perspectiva. Com base nas ações e medidas urbanísticas apontadas para as cidades - apoiadas em diversas discussões entre arquitetos, planejadores e administradores - sobre o urbanismo, surgiram as propostas modernistas que estabeleceram projetos para a organização das cidades. Está claro que, na perspectiva modernista, muitas outras dimensões estão incorporadas, por vezes contraditórias, do ponto de vista da política, da reflexão filosófica e da pretensão de aprimoramento técnico, moral e do pensamento, que resultariam na realização utópica e pretenciosa - porque acrítica - de um mundo melhor e democrático, fundamentado em avanços tecnológicos acessíveis à comunidade como um todo. No centro dessa concepção reside a arquitetura e urbanismo como eixo. Organizar os edifícios e o espaço urbano é organizar a sociedade.

\section{Um panorama do design das cidades e o desenvolvimento urbanístico}

No início do séc. XIX, os Estados Unidos alcançaram um grande crescimento industrial que acelerou o desenvolvimento urbano, especificamente na llha de Manhattan (Nova lorque), que cresceu de forma desorganizada. Em função disso, o governo da cidade criou uma 
comissão, que durante quatro anos, desenvolveu projeto de urbanização com implementação datada em 1811. Foi nesse momento que se aprimorou a concepção dos parques como espaço público no século XIX. Como exemplo da reformulação temos, a Reforma de Haussmann em Paris, e o Movimento dos Parques Americanos, o Park Moviment, liderado por Frederick Law Olmstead ${ }^{1}$, autor do projeto do Central Park em Nova lorque, e teve seus trabalhos desenvolvidos naquela cidade, em Chicago e Boston.

Gorski (2010) pontua que o final do século XIX e o início do século XX foram marcados pelo período do higienismo na Europa, e em diversas cidades do continente americano que vinham sofrendo com o intenso crescimento populacional resultante dos reflexos da Revolução industrial. O higienismo vai resultar nos primeiros relatos do urbanismo sanitarista, que tem como objetivo melhorar as condições das cidades quanto a sua salubridade para conter o avanço de graves problemas de saúde pública, causados pela falta de esgoto e poluição de rios. Tal preocupação fez com que as cidades fossem repensadas, também levando em consideração a funcionalidade e a estética.

Com o novo ideal urbano de estudar os males causados pelos avanços de expansão das cidades industrializadas, os teóricos da época defendiam dois eixos. O primeiro, que acreditava no projeto de recomeçar do zero a construção de cidades, com novas formas de organização de convivência, baseadas em teorias utópicas. Nesse eixo, os estudiosos focaram em colocar em prática o redesign das cidades com estudos de novas propostas urbanas, como Owen², Fourier ${ }^{3}$, Cabet ${ }^{4}$. O segundo eixo tinha como objetivo, resolver os

\footnotetext{
${ }^{1}$ Frederic Law Olmsted, proeminente arquiteto paisagista americano, cuja importância vai muito além de sua mais conhecida obra, o Central Park, de Nova lorque. Jornalista por profissão, antes de se tornar o influente projetista de parques. Frederick foi mais do que tudo, um dos maiores conservacionistas americanos, responsável por parques nacionais como o das cataratas do Niagara, entre outros. Sua concepção como desenhista da paisagem foi tão importante, que não seria de todo incorreto dizer que foi ele quem inventou e consolidou a profissão de arquiteto paisagista (www.olmsted.org).

2 Robert Owen: nascido em 14 de maio de 1771, Newtown, Montgomeryshire, País de Gales, morreu em 17 de novembro de 1858, Newtown, o fabricante galês tornou-se reformador, um dos defensores mais influentes do século 19 do socialismo utópico. Seus moinhos New Lanark em Lanarkshire, na Escócia, com seus programas de assistência social e industrial, tornaram-se um lugar de peregrinação para estadistas e reformadores sociais. Ele também patrocinou ou incentivou muitas comunidades "utópicas" experimentais, incluindo uma em New Harmony, Indiana, EUA (www.britannica.com).

${ }^{3}$ Charles Fourier: nascido em 7 de abril de 1772, Besançon, França, morreu em 10 de outubro de 1837, Paris), teórico social francês que defendeu uma reconstrução da sociedade baseada em associações comunais de produtores conhecidas como falanges. A falange, na concepção de Fourier, seria uma comunidade agrícola cooperativa responsável pelo bem-estar social do indivíduo, caracterizada pela contínua mudança de papéis entre seus membros. Sua ênfase na adaptação da sociedade às necessidades humanas e no desperdício do sistema capitalista competitivo prefigurava as ideias de Karl Marx.Os assentamentos cooperativos baseados nas ideias de Fourier foram iniciados na França e especialmente nos EUA, entre os quais os mais conhecidos foram o Brook Farm, de curta duração, em Massachusetts (1841-46) e a Phalanx norte-americana no Red Bank, Nova Jersey (www.britannica.com).

${ }^{4}$ Étienne Cabet: socialista francês e fundador de um assentamento comunal em Nauvoo, III. Após uma carreira de professor, advogado, revolucionário e exílio político, Cabet publicou uma novela, Voyage en Icarie (1840), apresentando suas teorias sobre a comunidade ideal. Buscando colocar suas ideias em prática, ele e várias centenas de seguidores chegaram em Nova Orleans em 1848 e 1849. Ele comprou o antigo assentamento Mórmon em Nauvoo e levou 280 colonos lá para começar a Icaria. O acordo foi na melhor das hipóteses um compromisso, pois Cabet não pôde colocar em prática muitas de suas ideias. A população nunca excedeu 1.800. Em 1856 surgiram dissensões, e Cabet partiu com 180 seguidores para São Luís, onde ele morreu em breve. As colônias
} 
problemas pontuais na cidade, sem se preocupar com uma visão geral, a fim de encontrar soluções isoladas para cada um desses problemas, focando seu projeto em termos jurídicos e técnicos, criando novas regulamentações e efetivando a legislação urbanística moderna.

O discurso de redesign das cidades gera um questionamento em oposição à industrialização dando origem às teorias urbanísticas e aos projetos das cidades-jardim, dos urbanistas chamados utópicos, como Ebenezer Howard, Arturo Soria y Mata e Tony Garnier, como comenta Lins (1998, p. 3):

Estas três propostas, de certa maneira, introduziram novos conceitos de desenho urbano inéditos até então. Suas influências se fizeram sentir de várias maneiras. As Cidades Jardins de Ebenezer Howard, por exemplo, tiveram reflexo até o segundo pós-guerra na ocupação dos subúrbios jardins das cidades inglesas e norteamericanas. Soria y Mata propôs uma forma de unir os núcleos urbanos por meio de uma Cidade Linear, propondo a ruralização da vida urbana. Tony Garnier introduziu no pensamento urbano a noção do zoneamento das funções urbanas com sua Cidade Industrial, influenciando posteriormente a Le Corbusier e a Carta de Atenas.

No ano de 1892, Soria y Mata divulga sua proposta de cidade linear, no jornal "El Progresso de Madri". Sua proposta estava diretamente ligada à sua preocupação com a forma das cidades industriais e sua organização circular, o que segundo ele, gerava congestionamento nas áreas centrais, valorização de terrenos centrais e marginalização da periferia. Para Soria y Mata, a cidade linear deveria ser situada entre duas cidades já existentes, havendo uma única avenida (com largura aproximada de 40m), ligando-as. Em sua proposta, além de apontar as medidas dos terrenos, ocupação dos lotes e áreas verdes, também criava uma área para plantações, além de defender a instalação de uma linha férrea ao longo da via, para ajudar os trabalhadores na locomoção ao trabalho.

Soria y Mata foi responsável pela primeira companhia de bondes da cidade de Madrid, e sua proposta tinha como prerrogativa a correlação das moradias dos trabalhadores e as infraestruturas urbanas, podendo, dessa forma, acreditava o autor, evitar a marginalização da periferia, além de propor que a cada lote familiar houvesse um jardim para cultivo, amenizando a relação cidade-campo, como descreve Mota (1997, p. 124):

\begin{abstract}
Nestas declarações de Soria, estão presentes dois factores de importância fundamental: a universidade da sua proposta e a resolução da dicotomia cidadecampo. A aposta de Soria num desenvolvimento linear, simbolizado pela linha recta de extensão ilimitada, diz bem dos seus propósitos. Não se trata de efectuar uma proposta localizada, resolvendo uma solução particular, mas sim de uma proposta com a intenção de se constituir como um modelo universal de construção de cidades. A outra grande inovação, promovida pela ideia de Soria, é a da abolição da cidade-ponto, promotora de centralidade e hierarquia, em favor da criação da
\end{abstract}

de Icarians foram estabelecidas em Cheltenham, perto de St. Louis; em Corning, lowa, dissolvido em 1884; e em Cloverdale, Califórnia, dissolvido em 1895 (www.britannica.com). 
cidade-linha, uniforme e igualitária. Assim se propunha a ruralizar a vida urbana com a proximidade de cada ponto da cidade linear ao campo, que por consequência se urbanizava por se encontrar em contacto permanente com o organismo urbano. Ruralizar a cidade e urbanizar o campo haveria de se constituir como o lema da Cidade Linear.

Em 1898, Ebenezer Howard, através de sua publicação intitulada Tomorrow e posteriormente reimpresso em 1902 com o título Garden-cities for Tomorrow (1902), propõe o modelo de cidade jardim relacionado com a qualidade ambiental, que, como descreve Mota (1997, p. 172), tem "importância indiscutível para o urbanismo do nosso século", já que tinha como ideal, a "resolução do problema da sobrelotação dos grandes centros, provocada pelo êxodo maciço das zonas rurais para as cidades".

As propostas urbanas de Tony Garnier ${ }^{5}$ na França, Walter Gropius ${ }^{6}$ na Alemanha e Hendrik Petrus Berlage na Holanda (urbanistas progressistas e racionalistas), procuravam projetar cidades com a preocupação não apenas de soluções utilitárias, mas também plásticas, dentro da concepção modernista de reformulação estética análoga à transformação social.

O arquiteto francês Tony Garnier, considerado primeiro arquiteto urbanista do século $X X$, enfocava a cidade industrial, que compreendia duas grandes extensões: residencial e industrial, ambas separadas por uma área verde. Para sua implantação, era necessária a existência de uma fonte geradora de energia (por exemplo rio), áreas verdes e via férrea, e tinha como possibilidade a expansão, para atender além de 32 mil habitantes. Seu projeto se caracterizava pela implantação de casas isoladas, com área verde, possuindo no máximo dois pavimentos, havendo possibilidade de compra de outro lote para expansão da residência. Lins (1998, p.12) afirma que "grandes autores reconhecem em Tony Garnier um marco no planejamento urbano moderno", ao descrever que Françoise Choay classifica-o como um "Urbanista Progressista" (1965, p. 31) e que Pierre Bourdeux declarava Tony Garnier um dos "pais da carta de Atenas, pois sua Cidade Industrial já propunha a separação das funções, como produção, moradia e saúde".

\footnotetext{
5 Tony Garnier: nasceu 13 agosto de 1869 em Lyon na área de Croix-Rousse. Confrontado em uma idade jovem para as condições de vida dos trabalhadores industriais, ele vai querer cedo, através de sua paixão, a arquitetura, encontrar uma maneira de responder ao problema da habitação social. Inventar uma nova maneira de pensar sobre habitação será uma de suas principais preocupações. Em 1889, ele se mudou para Paris, onde tentou seis vezes a competição do Grand Prix de Roma e vence em 1899, levando ele a trabalhar por quatro anos, como residente na Villa Medici, a fim de estudar os monumentos antigos (www.museeurbaintonygarnier.com).

${ }^{6}$ Walter Gropius: nascido em 18 de maio de 1883, Berlim, Alemanha, morreu em 5 de julho de 1969, Boston, Massachusetts, EUA), arquiteto e educador alemão americano que, particularmente como diretor da Bauhaus (191928), exerceu uma grande influência no desenvolvimento da arquitetura moderna. Seus trabalhos, muitos executados em colaboração com outros arquitetos, incluíram o prédio da escola e a faculdade habitacional na Bauhaus (192526), o Harvard University Graduate Center e a Embaixada dos Estados Unidos em Atenas (www.britannica.com).
} 
Esse ideal racional e progressista do urbanismo culmina com a criação dos C.I.A.M., Congressos Internacionais de Arquitetura Moderna em 1928, que tinha como objetivo formular o problema arquitetônico contemporâneo, apresentar ideias da arquitetura moderna de maneira internalizada em grupos econômicos, sociais e técnicos, além de zelar pela solução dos problemas da arquitetura. O 1ํㅡ. C.I.A.M., sediado na Suíça, tinha como temas abordados a padronização, a economia, a urbanística, a educação da juventude e a realização da arte para a elite (a arquitetura e o Estado).

Iniciado em Frankfurt, no ano de 1929, o 2 ․I.A.M. se preocupou em discutir os

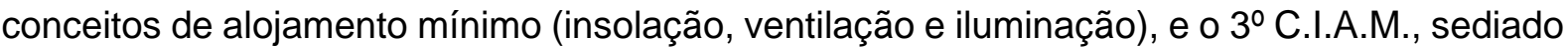
em Bruxelas em 1930, priorizou o estudo do loteamento racional e o problema da forma. Mas foi no $4^{\circ}$ C.I.A.M., no ano de 1933, sediado em um navio que saiu de Marselha com destino a Atenas, com o tema "Cidade Funcional", no qual os participantes analisaram e relataram as atividades produzidas na cidade como o tráfego viário, áreas públicas e residenciais, gerando a famosa Carta de Atenas.

A Carta de Atenas sintetiza o conceito de urbanismo moderno racionalista/funcionalista que tinha como ideia inicial o fato de que as questões econômicas e sociais têm relações com as transformações da arquitetura, já que abordaram o problema da cidade que diz respeito a habitação, lazer, patrimônio histórico, circulação, entre outros.

O documento contribuiu para a elaboração de planos urbanísticos posteriores, à medida que ressaltou os aspectos essenciais ao planejamento urbano na organização das cidades, como o zoneamento funcional, a circulação de veículos desassociada da circulação dos pedestres e uma organização visual geométrica. De acordo com Sabbag (2012) após a inserção dos eixos fundamentais do urbanismo moderno (habitar, trabalhar, recrear e circular) na Carta de Atenas, o documento ficou por 30 anos, orientando as práticas arquitetônicas e urbanísticas modernistas, influenciando muitos modelos apresentados para países da Europa, Estados Unidos e Brasil.

Sabbag (2012, p. 32) afirma que "algumas cidades são planejadas e construídas - como Brasília e Palmas, La Havre (França), Tel-Aviv (Israel) - mas a grande parte dos projetos se confronta com a cidade existente", como por exemplo São Paulo e Rio de Janeiro, que tiveram mudanças aplicadas a áreas vizinhas ao traçado urbano existente. Mas nem todas as intervenções relacionadas às propostas urbanísticas foram realizadas de maneira equilibrada, havendo "intervenções mais ou menos agressivas, com um diálogo mais ou menos amigável, com proposta de uma cidade moderna sobre a cidade tradicional", que influenciaram as grandes obras em cidades europeias, americanas e brasileiras, conduzindo intervenções radicais de melhoramento urbano de caráter racionalista.

Nos anos de 1950 e 1960, os projetos urbanos modernos chegam em seu ponto máximo de aplicação nas cidades, havendo uma devastação nos grandes centros. Com o esforço de 
implantar esse ideal moderno nas cidades, os projetos urbanos modernistas acreditam que a cidade poderia ser destruída, perdendo seus elementos históricos, para dar lugar ao plano rígido e racional, em prol dessa "modernidade", como relata Sabbag (2012, p. 32):

O urbanismo moderno despreza, "arrasa com a cultura encontrada em uma determinada cidade para, assim implantar seu modelo autoritário, rígido, racional. Segundo Choya, até a década de 1960, há um ideário de modernização e de destruição construtiva onde o patrimônio no contexto do urbanismo moderno, por mais apreço que tivesse por parte da população, é extinto em nome desta nova concepção de fazer a cidade.

O crescimento urbano e o colapso da cidade moderna, desencadeados pela crise econômica, faz nos anos 1970 e 1980, com que o planejamento urbano seja repensado, dando origem ao planejamento estratégico. Essa proposta de planejamento, empregada inicialmente pelas empresas americanas, visa ações coordenadas, sendo instrumento de planejamento empresarial (Sabbag, 2012), articulando de forma clara o enfoque financeiro na perspectiva urbanística.

\section{Apropriação do espaço e museus: uma reflexão a partir das práticas artísticas}

Para Freire (2006, p. 10), a arte conceitual possibilitou uma "atitude crítica frente às instituições, notadamente o museu e possibilitou pensar em formas alternativas de circulação das proposições artísticas".

A arte conceitual de matriz norte americana enfatizava o processo de pensamento em detrimento da materialidade física. Seus adeptos acreditavam em uma maior valorização do conceito e da ideia que existia por trás da obra de arte, sendo mais importante até que o resultado final, e que esse (objeto) poderia se tornar completamente obsoleto:

Durante os anos 60, os anti-intelectuais e emocionais/intuitivos processos de produção artística - característicos das duas últimas décadas - começaram a ceder lugar a uma arte ultraconceitual que enfatiza quase exclusivamente o processo de pensamento. À medida que o trabalho é projetado no estúdio - mas executado em outro lugar por um artífice profissional -, o objeto se torna meramente produto final, e muitos artistas perdem interesse pela evolução física do trabalho de arte. $O$ ateliê vai novamente se tornando um [local de] estudo. (LIPPARD; CHANDLER, 2013, p. 151).

Essa nova forma de compreender a arte fez surgir diversas ações e performances nas cidades, ocorrendo, com isso, uma alteração da noção de artista durante aquelas décadas:

As artes visuais, no momento, parecem pairar numa encruzilhada que bem se poderia revelar como duas estradas para um mesmo lugar, apesar de aparentarem vir de duas fontes: arte como ideia e arte como ação. No primeiro caso, a matéria é negada, pois a sensação foi convertida em conceito; no segundo caso, a matéria foi transformada em energia e tempo-movimento. (LIPPARD; CHANDLER, 2013, p. 151). 
No momento em que a produção artística sai dos museus e galerias - espaços consagrados, com um conjunto de objetos expostos, onde reinava a contemplação, e espectadores mantinham a distância das obras a segurança do acervo e perpetuação de uma relação aurática - e invade as ruas, passa a registrar os processos de criação através de fotografias, vídeos e áudio, tornando esses elementos constituintes da obra.

As novas concepções artísticas, na década de 1970 questionavam o modelo tradicional de museu, provocando um novo posicionamento dessas instituições diante de um novo paradigma:

As experiências que nos anos 70 opunham-se teórica e praticamente ao caminho adotado pelos museus clássicos, de caráter enciclopédico, desaguaram caudalosas nos anos 80 , permitindo a construção de veredas alternativas e a busca de sistematização teórico-experimental. (CHAGAS, 2002, p. 57).

Com toda a experimentação que as propostas conceituais trouxeram, os artistas se preocupavam de maneira enfática com o ambiente em que sua obra seria exposta, pois o espaço de relações dos públicos com as obras deveria ser também repensado, já que os artistas questionavam a rigidez formal e exigiam que o processo pelo qual a obra foi realizada passasse a ser explicitado e documentado. Além disso, não são poucas no período as propostas que encaram o ambiente como obra, exigindo uma ampliação e alteração também dos parâmetros pelos quais a produção é compreendida:

O que posteriormente se questionou é onde a obra de arte pode ser encontrada e isso faz com que "o objeto de arte se desmaterialize, confunda-se com a vida cotidiana, revele-se em processo, ocupe espaços expandidos e diferenciáveis. (FREIRE, 2006, p. 25).

As práticas artísticas, a partir dos anos 1960 e 1970, ultrapassam os meios tradicionais de exposição da arte, como museus, teatros e galerias, fazendo com que alguns artistas encontrem os espaços urbanos das cidades como local de suas práticas. Dessa forma, criase um questionamento crítico sobre o diálogo da arte e da arquitetura contemporânea, já que o fio condutor conceitual dessa produção tinha como pauta críticas nas áreas políticas, sociais e culturais advindas do processo de extrema e urbanização das cidades, fomentado pelo consumo e exigências na alteração da vida cotidiana.

No campo da arte nos anos 1960 e 1970, Tidei e Sperling (2015), a interação com o público, conceito de autoria e os processos de produção da obra de arte estavam em questionamento, fazendo com que os artistas aproximassem as práticas artísticas da vida cotidiana, o que gerou uma ampliação ao espaço urbano das cidades:

Se, por um lado, a instalação dessas obras fora do espaço privilegiado da galeria parece indicar que elas abrem mão de seus status de obra de arte e de sua função cultural, por outro lado, parece refletir também a preocupação com a experiência do 
sujeito com a obra, na medida em que o espaço urbano passa a ser concebido como um espaço privilegiado de fruição, que possibilita o contato com um número maior de pessoas. (PEREIRA JÚNIOR, 2011, p. 321).

Já na arquitetura, os debates eram em função do seu engajamento político e social, da sua nova determinação conceitual e de conexões com outras áreas do conhecimento, decorrente principalmente da crítica aos pressupostos modernistas. Desse processo, 0 diálogo com a cidade também sofreu alteração e passou não só a ver a cidade como um espaço funcional mecânico, mas também como um local de produção de cultura:

Algumas posições foram então reformuladas com relação à cidade, que deixou de ser tomada como espaço voltado a um funcionamento mecânico eficiente, e passou a incorporar uma dimensão cultural e simbólica. O lugar, no sentido fenomenológico, ganhou força nesse período; deslocava-se assim a ênfase conferida ao "plano" para uma relação com o espaço no sentido "existencial", valorizando a sua percepção sensorial e simbólica. As questões relativas à individualidade do corpo e do lugar vieram tensionar a ênfase conferida ao homem-tipo e à "máquina de morar", parâmetros da funcionalidade e racionalidade do espaço. (TIDEI; SPERLING, 2015, p. 65)

Assim, ao considerar-se esses novos conceitos e posicionamentos em relação à arte, à arquitetura e ao urbano, encontra-se um entrelaçamento que realiza experimentações no espaço urbano em termos performáticos e de habitação do espaço. Entre os artistas que se posicionam nesse processo destaca-se o arquiteto/artista Gordon Matta-Clark, que elaborou "um pensamento da arte que articula a prática artística ao ativismo social, tal qual se faz possível notar nas intervenções urbanas" (VASCONCELLOS, 2012, p. 143), bem como em suas ações de performances e happenings.

\section{Rupturas na arte e nas obras de Gordon Matta-Clark}

Nascido em Nova York no ano de 1943, Gordon Matta-Clark é um dos artistas mais influentes da década de 1970 por explorar e subverter a arquitetura urbana como princípio inventivo. Filho do pintor e arquiteto surrealista Roberto Matta, estudou arquitetura em Ithaca, NY, na Cornell University (1962), deixando a Universidade em 1968. No ano de 1969, conheceu Robert Smithson ${ }^{7}$ e posteriormente Dennis Oppenheim ${ }^{8}$, com quem teve relação de trocas intelectuais e artísticas (CIDADE, 2008). Após a conclusão de seus estudos, mudou-

\footnotetext{
${ }^{7}$ Robert Smithson: artista nascido em New Jersey, em 02 de janeiro de 1938. Smithson é mais conhecido por sua obra provocante feita na terra, SpiralJetty, feito em 1970. Ele ganhou reconhecimento internacional por sua arte inovadora que não foi limitada por gênero ou materiais, bem como por seus escritos críticos que desafiou as categorias tradicionais da arte entre os anos de de 1964-1973. Sua arte e escritos tiveram um profundo impacto na escultura e teoria da arte há mais de 30 anos (www.robertsmithson.com).

8 Dennis Oppenheim: nascido em 06 de setembro de 1938, foi um artista conceitual, artista da terra, escultor, fotógrafo e artista de performance, que foi fundamental para a arte e os movimentos iniciais da Land Art Performance. Oppenheim nasceu em Electric City, WA, e obteve seu diploma de Bacharel em Artes Plásticas pela Faculdade Califórnia de Artes e Ofícios em Oakland, CA, em 1964. Oppenheim passou a estudar na Universidade de Stanford em Palo Alto, CA, onde ganhou o mestrado de Belas Artes em 1965 (www.artnet.com).
} 
se para Nova York e se tornou uma figura bem conhecida entre os artistas no SoHo, suas experiências e práticas artísticas no bairro são consideradas como uma das mais significativas de sua carreira. Foi dos encontros com os artistas citados, que Matta-Clark criou uma "obra intensa e prolífica que articulou preocupações arquitetônicas, relacionando arte e cidade, ativismo político e práticas artísticas" (VASCONCELLOS, 2012, p. 148).

Com a expansão da arte, a materialidade vai transformar o fazer artístico, alterando os suportes e questionando o sistema da arte que vai modificar o estatuto da obra de arte, inclusive das instituições que a legitimam. Nesse momento que a produção artística de MattaClark invade as ruas, inicia-se, também do ponto de vista da urbanização um movimento de reestruturação como ampliação de vias, criação de áreas verdes e bulevares, entre outras, em muitas das grandes cidades norte-americanas e europeias, desencadeando um processo de degradação e intervenções urbanas, ao mesmo tempo que uma reflexão sobre história, memória e materialidade da cidade e da cultura.

As experiências artísticas de Matta-Clark foram iniciadas a partir de seu encontro com Jeffrey Lew e Holly Solomon. Diserens (2006) descreve em seu livro, que Solomom buscava encontrar uma galeria, quando, por meio de Jeffrey Lew, foi apresentada para Matta-Clark, que acabou sendo seu guia pelo bairro do SoHo. Mas foi através de um coletivo informal de escultores e bailarino, que Jeffrey Lew, contribuiu para o desenvolvimento das ideias de Matta-Clark, ao liberar o acesso e utilização de alguns espaços do seu prédio em Nova York - SoHo, para uso livre dos artistas, e também para ocupação de Matta-Clark.

Mas tarde, Matta-Clark desenvolve uma técnica de corte/interferência em edifcios, que iria posteriormente ser usada em prédios abandonados que ele encontra em torno de Nova York. Mas foi na ocupação no prédio de Jeffrey Lew, que fez suas primeiras experiências com cortes. O prédio tinha acesso fácil ao metrô, e Matta-Clark cavou o chão de terra do porão, com o intuito de plantar uma cerejeira no fundo do buraco, para minar as fundações e libertar a terra, já que tinha a compressão que ela era confinada pelo edifício construído acima, obra denominada pelo artista de Cherry Tree (DISERENS, 2006).

Em abril de 1971, com a possibilidade de utilizar espaços externos, sem a limitação da escala e limites impostos pelas galerias, o artista se aproveitou de um convite de grupo-show de Vassar College. Com a obra Tree dance (1971), na qual ele se apropriava dos espaços vazios criados com redes de náilon colocadas por entre as árvores, em forma de pequenos casulos, onde o único acesso seria através de escadas em cordas e um balanço; o trabalho de Matta-Clark, promove uma ação coletiva que contava com dançarinos e artistas, saindo do seu habitual trabalho solitário. Nessa performance, os atores, que se encontravam dentro desse espaço, produziam movimentos dando entender a possibilidade de ocupação das áreas vazias. 
Em 1973 Matta-Clark iniciou suas experiências artísticas com cortes e retiradas de partes existentes de edifícios. Por meio dos trabalhos de apropriação e desconstrução de casas abandonadas ou vazias, o artista ampliou sua rede de atuação. Em 1974, realizou sua primeira intervenção significativa, através da aquisição de uma casa de madeira localizada no subúrbio de Nova Jersey, datada pós-Segunda Guerra Mundial, que estava pronta para ser demolida para dar lugar à renovação. Foi através de Holly e Horace Salomon (DISERENS, 2006), que Matta-Clark adquiriu um prédio inteiro com o qual ele poderia trabalhar sua ideia, que intitulou de Splitting.

Ao intervir na casa, ele produziu um rasgo de cima a baixo, seccionando-a ao meio e suspendeu uma das metades da edificação em sua base, deixando-a levemente. O edifício foi, em seguida, apoiado em um dos lados através de macacos, e suas fundações foram ligeiramente reduzidas vindo a metade da casa a se apoiar nas fundações mais baixas, dando abertura no corte e revelando uma forma de espaço vazio que dividia a casa. Desta forma, Matta-Clark não só alterou a noção de estabilidade relacionada à moradia da classe média americana, mas também libertou o padrão uniforme da arquitetura de casas, que se tornou característica de alienação suburbana.

Outra intervenção do artista, a Jacob's Ladder (1977), foi um trabalho no qual tinha como ideia o desenho no espaço. Esta obra foi realizada para a Documenta 6, quando foi chamado pelo comité do evento para participar da exposição em Kassel. Outros trabalhos posteriores de Matta-Clark, como Days End (1975) e Conical Intersect (1975) apresentaram diferentes intervenções nos edifícios, além do corte ao meio linear já comum em seus projetos, inovou com formas circulares e cônicas. Em Nova York, com a falta de interesse comercial na área portuária, cais e armazéns, proporcionou a Matta-Clark a oportunidade de ter acesso facilitado nesses móveis.

Matta-Clark interferia nos edifícios, através de vários cortes circulares e ovoides que traspassavam a estruturas dos andares, removendo as seções das paredes. Suas intervenções não ficavam apenas nas estruturas das paredes, ele também interferia com recortes em pisos estruturais de madeira resistente, onde seccionava os fossos. Os projetos ainda contavam com as ousadas críticas que o artista fazia para as áreas degradadas ou pela condenação de demolições de prédios em perfeitas condições para fins de "modernização urbana".

Suas intervenções no âmbito social se expandiram do espaço urbano dos bairros de periferia de Nova York, onde o diálogo do artista com o espaço público marcou de forma significativa a experiência e a prática artística; e sua obra provocou impacto ao apontar a presença transitória de monumentos da cultura urbana, havendo apenas o registro dos processos de criação através de fotografias, vídeos, tornando esses elementos, a única prova física de suas obras efêmeras. 
O século $X X$ trouxe um novo olhar sobre o design das cidades e sua reorganização, fato esse que era reforçado nos conceitos das obras de Matta-Clark. É possível estabelecer entre a obra de Matta-Clark e os problemas da urbanização na segunda metade do período, que resultou em um processo de descaracterização das cidades fomentando assim, de acordo com ICOM - International Council of Museums (s.d.), uma preocupação com a memória, história e cidades. Nesse período dos anos 70 (1970) o Conselho da Europa, na Carta Europeia do Patrimônio Arquitetônico n.ำ 1, ampliou o conceito de patrimônio para ambientes humanizado e edificado. Essa concepção possibilitou uma valorização da memória coletiva e social do patrimônio, por revelarem a Identidade das cidades, conceito esse que é possível articular com aquele explorado por Matta-Clark na obra Conical Intersection, na qual utiliza um prédio em boas condições no centro de Paris para questionar a demolição desnecessária de uma área.

Foi com esse projeto, executado para a Bienal de Paris, em um prédio que seria demolido em função da modernização da área, para dar lugar ao Centro Georges Pompidou, de Richard Rogers e Renzo Piano, ele teve seu maior reconhecimento, sendo considerado um dos principais projetos do artista.

Nas duas edificações datadas do século XVII, o artista fez um corte de abertura maciça de $4 \mathrm{~m}$ de diâmetro. Assim, os transeuntes podiam vislumbrar o edificio através do rasgo cortado, de forma que seu centro chegava à altura do quarto andar de onde direcionava a atenção para baixo, evidenciando a rua principal de Paris, que, segundo o artista, era uma maneira de denunciar a violência daquela intervenção urbana.

As ações de Matta-Clark podem ser vistas em documentações fotográficas e vídeo que são registros de suas intervenções, pois como descreve Freire (2006, p. 10), é "nesse momento que as performances, instáveis no tempo, e as instalações, transitórias no espaço, tornaram-se poéticas significativas", tornando de fundamental importância, as diversas performances/intervenções do artista. Matta-Clark era um artista que participava ativamente de ações comunitárias. Participou de uma articulação com um grupo de artistas que ocuparam um restaurante abandonado para desenvolver práticas de happenings, cursos e intervenções em forma de "restaurante-oficina-criativo", chamado de Food - Comidas Criollas.

O trabalho de Matta-Clark, foi escolhido para análise do tema proposto, por se perceber o que há no interior de suas práticas a dinâmica da transgressão/reconhecimento, pois é através dessa dinâmica que funciona a ficção poética, tão presente na arte contemporânea. Gordon Matta-Clark pode ser analisado tanto sob o ponto de vista de sua ação conceitual no espaço, como pela relação, derivada da primeira, que ele estabelece entre o sujeito e o espaço. As suas intervenções caminham para a descoberta do movimento que envolve o ato criativo estabelecendo relações entre sujeito, arquitetura e lugar. 
Além do espaço urbano e da arquitetura, Matta-Clark também se envolveu nas questões institucionais do espaço museológico. Participando da exposição coletiva do Institute for Architecture and Urban Studies (IAUS), no ano de 1976, expôs fotos de edifícios de áreas degradadas do Bronx com vidros estilhaçados. Mas, foi através de sua obra Window Blowout, que ele enfatizou a crítica à organização institucional, ao quebrar todas as janelas do Instituto durante a noite que antecedia a inauguração do evento, colocando em xeque o conteúdo simbólico da própria organização que o suporta (WISNIK, 2010).

\section{Conclusão}

É importante destacar que Matta-Clark praticava suas intervenções em locais que estavam para ser demolidos, fazendo de seus cortes precisos e suas intervenções não só um espaço urbano desconstruído, mas sim reconstruído e ressignificado através da mutilação interna dos edifícios. Suas intervenções escultóricas, com seus "cortes de construção", criavam rasgos nos edifícios antigos e tratava-os como esculturas, criando composições espaciais documentadas em filmes e fotografias, que posteriormente eram, ao lado de fragmentos dos próprios edifícios, expostas em galerias. Pode-se considerar que a importância deste tipo de ação explicita a decadência urbana das cidades dos anos 1970, em especial de Nova York, na concepção de seus trabalhos. Neste contexto, o artista criticava a arquitetura como construção simbólica e seu consumo através das cidades no que diz respeito ao descaso com os bairros suburbanos e à uniformidade das fachadas através das leis de zoneamento.

Pode-se considerar que Matta-Clark questiona o sistema tradicional da arte através de sua estratégia poética de intervenções no espaço urbano. Produzia arte na periferia ou nos bairros suburbanos, recusando o mercado de arte com suas obras efêmeras

A ocupação da arte de Gordon Matta-Clark, nos espaços além institucionais, problematiza a metrópole, as questões sociais que se desdobram no desenvolvimento do design urbano moderno, articulando essas variáveis com sua criação artística plástica, realizando sua obra nas dependências da cidade, no urbano público, ou seja, nas áreas da cidade onde são de usufruto da população que habita a mesma, fora dos limites das galerias de arte e museus, o artista fazia dos registros de vídeos e fotografias, sua forma de salvaguardar a memória de sua obra. Seu trabalho em projetos mais amplos, reforça o questionamento da documentação museológica relacionada à memória coletiva, não só do lugar, mas do processo de concepção e conclusão da obra, não se podendo ter catalogação da obra, mas sim, apenas fragmentos desse registro.

A inquietação encontrada nas obras de Matta-Clark, está associada à história do bairro SoHo, em Nova lorque, que entre o abandono e a viabilidade de ocupação, possibilitou ao artista realizar um trabalho de intervenção arquitetônica, no qual seu processo focava 
experiências coletivas de apropriação e participação, e não em um interesse lucrativo nos espaços ocupados por eles. Gordon Matta-Clark inovou não apenas ao chamar a atenção para novas práticas artísticas e para uma sensibilidade urbana crítica, mas também por subverter as questões de tempo e de espaço e ao problematizar a instituição e o objeto da arte. O artista, ao utilizar em sua obra edifícios abandonados e em estado de deterioração, questiona as propostas modernas do urbanismo americano em vigor, nas décadas de 60/70, problematizando o modo de vida da sociedade capitalista e seu consumo na esfera urbana.

O estudo do design das cidades possibilitou uma nova percepção que começou a valorizar não só a memória artística convencional, encontrada nos museus, como os conjuntos arquitetônicos, espaços que antes foram descaracterizados em função do ideal de progresso. Essa investigação proporcionou uma reflexão sobre um possível hibridismo entre design urbano, arte e arquitetura e sua manutenção crítica.

Acreditamos que a obra de Matta-Clark, ao se propor desfazer os espaços da arquitetura moderna e seu ideal urbano, realizando intervenções em prédios abandonados ou condenados a demolição, questionou a autonomia e a lógica econômica, pós 1950, na qual os edifícios invadiram os espaços sem levar em conta sua função pública, levantando a possibilidade do desaparecimento da memória coletiva e das histórias dessas cidades, bem como a crítica a instituição do museu e o objeto artístico.

\section{Referências}

ARTNET. Dennis Oppenheim. Disponível em: http://www.artnet.com/artists/dennis-oppenheim/. Acesso em: jan. 2015.

BEVERIDGE, Charles E. Frederick Law Olmsted Sr.: landscape architect, author, conservationist (1822-1903). [online] National Association for Olmsted Parks. Disponível em: http://www.olmsted.org/the-olmsted-legacy/frederick-law-olmsted-sr. Acesso em 14 jan. 2016.

BIRKHOLZ, Lauro Bastos. O ensino do planejamento territorial. São Paulo: USP, 1967. Tese de Cátedra.

CHAGAS, Mario de Souza. Memória e Poder: dois movimentos. Cadernos de Sociomuseologia, Lisboa, ULHT, v. 19, n. 19, 2002.

CHOAY, Françoise. A Alegoria do patrimônio. Tradução: Luciano V. Machado. São Paulo: Estação Liberdade: UNESP, 2006.

CIDADE, D. M. Gordon Matta-Clark: arquitetura e apropriações. In: // Seminário Arte e Cidade: memória e contemporaneidade. Salvador: EDUFBA, 2008.

DISERENS, Corinne. Gordon Matta-Clark. [London:] Phaidon Press, 2006.

ENCYCLOPÆDIA BRITANNICA. Disponível em: https://www.britannica.com. Acesso em: 12 out. 2014.

FREIRE, Cristina. Arte conceitual. Rio de Janeiro: Jorge Zahar, 2006.

GORSKI, Maria Cecilia Barbieri. Rios e cidades: ruptura e reconciliação. São Paulo: Senac, 2010.

LINS, Antônio José Pedral Sampaio. A ferrovia e três utopias urbanas, ou como os pioneiros viam o trem: uma análise comparativa entre "Cidades Jardins, "Cidade Linear" e "Cidade Industrial". In: 
SEMINÁRIO DE HISTÓRIA DA CIDADE E DO URBANISMO, V; Cidades: temporalidades em confronto, Campinas. Anais [...]. Campinas: PUC-Campinas, v. 5, n. 2, p. 1-19.,1998.

LIPPARD, Lucy R.; CHANDLER, John. A desmaterialização da Arte. Tradução por Fernanda Pequeno e Marina P. Menezes de Andrade. Artes e Ensaios, Rio de Janeiro, UFRJ, n. 25, p.151-165, 2013.

MATTA-CLARK, Gordon. Desfazer o Espaço. Catálogo. Rio de Janeiro: Museu de Arte de Lima; Paço Imperial, 2010.

MOTA, Nelson Jorge Amorim. A cidade do sonho do desejo do desenho: utopias urbanas. Coimbra: Universidade de Coimbra, 1997. Disponível em https://estudogeral.sib.uc.pt/handle/10316/3739.

Acesso em: ago. 2015.

PEREIRA JÚNIOR, L. L. A aura da obra de arte pública: uma análise das intervenções artísticas no espaço urbano a partir do conceito benjaminiano de aura. Anais do II Seminario Internacional sobre Arte Público en Latinoamérica. Belo Horizonte: C/Arte, 2011. v. II. p. 318.

ROBERT SMITHSON. Introduction. Disponível em: http://www.robertsmithson.com/. Acesso em: 23 jan. 2015.

ROSENAU, Helen. A cidade ideal: evolução arquitetônica na Europa. Lisboa: Editorial Presença, 1988.

SABBAG, Juliane Albuquerque Abe. Brasília 50 anos: do urbanismo moderno ao planejamento estratégico. Brasília: Universidade de Brasília, 2012.

SCHULZ, Sônia H. Estéticas urbanas: da pólis grega à metrópole contemporânea. Rio de Janeiro, 2008

TIDEI, Mariana Dobbert; SPERLING, David Moreno. Práticas críticas no espaço urbano: Trisha Brown, Dane Michals e Bernard Tschumi, Oculum Ensaios, Campinas, v. 12, n. 1, p. 61-82, jan./jun.2015.

TONY GARNIER. Biography. Disponível em: http://www.museeurbaintonygarnier.com/. Acesso em 23 jan. 2015.

VASCONCELLOS, Jorge. A anarcoarquitetura de Gordon Matta-Clark: autonomismo político e ativismo estético, Visualidades, Goiânia, v. 10, n. 2, p. 139-137, jul./dez. 2012.

WISNIK, Guilherme. Arquitetura Arruinada. Novos Estudos CEBRAP, São Paulo, n. 87, jul. 2010. Disponível em: http://www.scielo.br/scielo.php?script=sci_arttext\&pid=S0101-33002010000200012. Acesso em: 16 nov. 2014. 